\title{
Oligonucleotides-A Novel Promising Therapeutic Option for IBD
}

\author{
Patrizio Scarozza ${ }^{1,2 \star}$, Heike Schmitt ${ }^{2}$, Giovanni Monteleone ${ }^{1}$, Markus F. Neurath ${ }^{2}$ and \\ Raja Atreya ${ }^{2 *}$
}

${ }^{1}$ Department of Systems Medicine, Gastroenterology, University of Tor Vergata, Rome, Italy, ${ }^{2}$ Department of Medicine 1 , Friedrich-Alexander-University of Erlangen-Nürnberg, Erlangen, Germany

\section{OPEN ACCESS}

Edited by:

Luca Antonioli,

University of Pisa, Italy

Reviewed by:

Maria Cecilia Giron, University of Padova, Italy

Antonio Di Sabatino,

University of Pavia, Italy

*Correspondence:

Patrizio Scarozza scarozzapatrizio@gmail.com

Raja Atreya

raja.atreya@uk-erlangen.de

Specialty section:

This article was submitted to Gastrointestinal and Hepatic

Pharmacology,

a section of the journal

Frontiers in Pharmacology

Received: 15 October 2018 Accepted: 14 March 2019

Published: 24 April 2019

Citation:

Scarozza P, Schmitt H, Monteleone G,

Neurath MF and Atreya R (2019)

Oligonucleotides-A Novel Promising

Therapeutic Option for IBD.

Front. Pharmacol. 10:314.

doi: 10.3389/fphar.2019.00314
Inflammatory Bowel Diseases (IBD), whose denomination comprehends Crohn's Disease (CD) and Ulcerative Colitis (UC), are intestinal chronic diseases that often require lifelong medical therapy. In the last two decades monoclonal antibodies against the cytokine TNF have become integral parts in the treatment of IBD patients, however there are unwanted side-effects and one third of patients show primary non-response while another subgroup loses response over time. Finding novel drugs which could act as therapies against precise pro-inflammatory molecular targets to avoid unwanted systemic side effects and additionally the process of immunization, represents an important aim for subsequent therapeutic approaches. Oligonucleotide based therapies represent a promising novel concept for the treatment of IBD. The molecular action of oligonucleotides ranges from inhibition of the translational process of mRNA transcripts of pro-inflammatory molecules, to mimicking bacterial DNA which can activate cellular targets for immunomodulation. Alicaforsen, selectively targets ICAM-1 mRNA. ICAM-1 is an adhesion molecule which is upregulated on endothelial cells during IBD, thereby mediating the adhesion and migration of leucocytes from blood to sites of active inflammation. In CD parenteral application of alicaforsen did not show therapeutic efficacy in phase II trials, but it demonstrated an improved efficacy as a topical enema in distal UC. Topical application of alicaforsen might represent a therapeutic perspective for refractory pouchitis as well. SMAD7 is a protein that inhibits the signaling of TGF $\beta$, which is the mainstay of a regulatory counterpart in cellular immune responses. An antisense oligonucleotide against SMAD7 mRNA (mongersen) demonstrated pre-clinical and phase II efficacy in $C D$, but a phase III clinical trial was stopped due to lack of efficacy. Cobitolimod is a single strand oligonucleotide, which mimics bacterial DNA as its CpG dinucleotide sequences can be recognized by the Toll-like receptor 9 on different immune cells thereby causing induction of different cytokines, for example IL10 and IFN $\alpha$. Topical application of cobitolimod was studied in UC patients. We will also discuss two other novel oligonucleotides which act on the GATA3 transcription factor (SB012) and on carbohydrate sulfotransferase 15 (STNM01), which could both represent novel promising therapeutic options for the treatment of UC.

Keywords: Crohn disease, ulcerative colitis, IBD, antisense oligonucleotide (ASO), target therapies 


\section{INTRODUCTION}

Inflammatory bowel diseases (IBD) are chronic inflammatory disorders of the intestine whose phenotypic spectrum mainly comprehends Crohn's disease (CD) and ulcerative colitis (UC). IBD are characterized by a chronic disease course with the alternation of active and quiescent phases, thereby requiring continuous follow up and management by health care systems (Maaser et al., 2019). In the last 20 years, there has been an increase in the prevalence of IBD from a percentage of 0.3$0.5 \%$ in North America and similarly in Northern Europe, Western Europe, and Oceania (Kaplan and Ng, 2017). Moreover, a profound rise in incidence was described in Asia and Latin America (Ng et al., 2018).

IBD patients often require treatment with immunomodulatory drugs such as thiopurines, methotrexate; biological drugs, like anti-Tumor Necrosing Factor (anti-TNF), anti-adhesion, or anti-interleukin 12/23p40 (IL12/23p40) antibodies and lately also Janus Kinase Inhibitors (JAKinhibitors). These different substance classes have become integral parts in the treatment of IBD patients; however there are unwanted, sometimes even severe side effects and over one third of patients show primary non-response while another subgroup of patients loses response over time (Roda et al., 2016). There is therefore the dire need for novel efficacious therapies with a favorable safety profile. Oligonucleotides represent an emerging substance class of targeted therapies with only limited systemic exposure to the drug, giving hope for a novel and rather safe treatment modality in IBD.

The molecular mechanism of action of oligonucleotides ranges from inhibition of the translational process of messenger ribonucleic acid (mRNA) transcripts of pro-inflammatory molecules, to mimicking bacterial deoxyribonucleic acid (DNA) which can activate cellular targets for immunomodulation.

Antisense technology is based on two principal different modes of action: activation of Ribonuclease $\mathrm{H}$ (RNase $\mathrm{H}$ ) or double-strand RNases. The activation of RNase $\mathrm{H}$ is mediated by the recognition of the sense-antisense heterodimer, after the binding of the single-strand oligonucleotide to the complementary target mRNA (Crooke, 2004). The heterodimer induces the activation of the RNase $\mathrm{H}$ enzyme, which inhibits the expression of the target mRNA (Aboul-Fadl, 2005). The second antisense mechanism is linked to the action of double-strand RNases which are activated by silence RNA (siRNA) molecules that are characterized by a double-strand oligonucleotide formed by a sense and an antisense RNA strand. After entering the cell, the antisense RNA recognizes the target cytoplasmic mRNA, forming a sense-antisense duplex, that is finally degraded by endogenous double-strand RNases (Crooke, 2004).

For the last 20 years, antisense technology has been improved in various fields of medical research. In 1999 the European Agency for the Evaluation of Medical Products (EMEA) approved Fomivirsen, as the first therapeutically used antisense oligonucleotide, developed for the treatment of Cytomegalovirus (CMV) retinitis. In the meantime many more oligonucleotide based substances have been tested in respective trials or already entered clinical practice: Macugen to treat age-related macular degeneration; Mipomersen for homozygous familial hypercholesterolemia; Eteplirsen for Duchenne muscular dystrophy; Defibrotide for severe hepatic veno-occlusive disease; and Nusinersen for the treatment of infants with types 1,2, and 3 spinal muscular atrophy (Stein and Castanotto, 2017).

This review focuses on pharmacodynamics and clinical perspectives of oligonucleotide based therapeutics so far studied for the treatment of IBD. (Supplementary Material).

\section{ALICAFORSEN}

Active inflammation in IBD is characterized by overexpression of adhesion molecules on endothelial cells that are centrally involved in mediating the gut homing of leukocytes. Inhibition of migration has become one of the established therapeutic approaches in IBD, with approval of the alpha4beta7 antibody vedolizumab for treatment of both IBD entities and ongoing clinical trials for many more therapeutic targets of the homing process (Sands, 2017; Zundler and Neurath, 2017). Intercellular Cell Adhesion Molecule-1 (ICAM1) is an adhesion molecule derived from the immunoglobulin superfamily acting as a ligand for the integrins expressed by leukocytes and represents one of the novel targets of antisense oligonucleotide (ASO) based therapeutic strategies (Mosli et al., 2014; Sands, 2017).

ICAM1 is overexpressed by endothelial cells during active disease in $\mathrm{CD}$ patients and its presence is thus diminished during remission. It was furthermore shown, that in UC patients the expression of ICAM1 in colonic tissue is higher than in respective controls (Jones et al., 1995; Vainer and Nielsen, 2000; Rivera-Nieves et al., 2008).

Preclinical studies have figured out the efficacy of a monoclonal antibody against ICAM1 administered topically in the experimental dextran sulfate sodium (DSS) murine model of colitis, which led to the reduction of mucosal inflammation (Hamamoto et al., 1999). When combined with anti-Vascular Cell Adhesion Molecule-1 (anti-VCAM1) or anti-alpha4 integrin antibodies, the ICAM1 antibody similarly exerted a positive effect on reducing the inflammatory response in a murine model of ileitis (Burns et al., 2001).

Alicaforsen is a 20-base phosphorothioate ASO that hybridizes the mRNA of ICAM1 and induces the hydrolysis of the DNA-RNA complex by an RNAse enzyme (Gewirtz and Sitaraman, 2001). A randomized trial of ISIS 2302, an ASO to ICAM1, was conducted in patients affected by severe rheumatoid arthritis, without evidence of significant efficacy, but with a good safety profile (Maksymowych et al., 2002). A pivotal phase I dose ranging trial conducted on healthy volunteers who intravenously received the ICAM1 ASO, showed good tolerance to the drug, with reproducible plasma levels and limited side effects (dose-related increase in activated partial thromboplastin time, clinical insignificant increases in complement factor C3a) at the time of the peak plasma concentration, without occurrence of associated clinical symptoms (Glover et al., 1997).

A dose ranging pharmacokinetic trial of high-dose alicaforsen randomized 22 patients with active $\mathrm{CD}$ to three alicaforsen treatment groups: 250-, 300-, or 350-mg doses, infused intravenously three times a week for 4 weeks. The authors 
evidenced a possible effectiveness of alicaforsen therapy in CD. Clinical remission was evidenced in $41 \%$ of all treated subjects and in $53 \%$ of those treated with more than three of the 12 infusions planned (Yacyshyn et al., 2002a).

A randomized trial of ISIS 2302, conducted in twenty CD patients, allocated to receive one of three different doses of this drug $(0.5,1$, or $2 \mathrm{mg} / \mathrm{kg})$ or saline placebo, evidenced a therapeutic success of the experimental drug, which was infused intravenously in 13 doses over 26 days (Yacyshyn et al., 1998; Reinisch et al., 2018). The remission rate after 1 month of therapy was $47 \%(7 / 15)$ in patients treated with the investigated substance and $20 \%(1 / 5)$ in patients treated with placebo. At the end of the 6 months follow up period, 5 of the 7 patients treated with the investigated substance maintained clinical remission and 33\% (5 of 15) successfully tapered concomitant corticosteroid treatment (Yacyshyn et al., 1998).

These positive perspectives about the steroid sparing effect of ISIS 2302 were not confirmed in a subsequent trial, which primary endpoint was steroid-free remission at week 14 . Here, 75 steroid refractory CD patients were randomized to four groups of treatment with ISIS 2302 or to placebo. The study drug was administered subcutaneously at four different dose-interval regimens $(0.5 \mathrm{mg} / \mathrm{kg}$ once daily for 2 days; $0.5 \mathrm{mg} / \mathrm{kg}$ five times a week for 1 week; $0.5 \mathrm{mg} / \mathrm{kg}$ five times a week for 2 weeks or $0.5 \mathrm{mg} / \mathrm{kg}$ five times a week for 4 weeks) (Schreiber et al., 2001; Lobaton et al., 2014). Steroid-free remission at week 14 was registered in only $3.3 \%(2 / 60)$ of patients treated with ISIS 2302 and in none of the placebo patients (Schreiber et al., 2001; Lobaton et al., 2014). This negative property to induce steroidfree remission was also confirmed by another study (Yacyshyn et al., 2002b). Here, 299 steroid-dependent CD patients were randomized into three treatment arms: ISIS $2302(2 \mathrm{mg} / \mathrm{kg})$ given intravenously three times a week for two weeks, vs. ISIS 2302 ( $2 \mathrm{mg} / \mathrm{kg}$ ) given intravenously three times a week for 4 weeks, compared to placebo application. Steroid free remission at week 14 was defined as the primary endpoint. It was reached by 20.2 and $21.2 \%$, respectively in the ISIS 2302 arm with treatment lasting 2 or 4 weeks compared to $18.8 \%$ in the placebo arm. Therefore, no statistical significant difference regarding clinical efficacy could be shown (Yacyshyn et al., 2002b).

The last clinical trial conducted in CD patients, which results were published in 2007, confirmed the inefficacy of alicaforsen in inducing clinical remission in CD patients. In this study, $331 \mathrm{CD}$ patients were randomized to two treatment groups: alicaforsen given intravenously, at a dosage of $100 \mathrm{mg}$ at the time of the first infusion, followed by $300 \mathrm{mg}$ given three times a week for 4 weeks $(n=221)$ compared to placebo administration $(n=110)$. The primary endpoint was clinical remission at week 12 . No statistical differences regarding clinical remission at week 12 were evidenced between the two treatment groups (33.9\% in the group treated with alicaforsen vs. $34.5 \%$ in the placebo group; $p=0.89$ ) (Yacyshyn et al., 2007). These results have led to the halt of further clinical studies of this compound in CD patients.

In UC, some clinical studies demonstrated efficacy of alicaforsen in inducing clinical response and remission via topical application. First, an effective induction of clinical response by topical application of alicaforsen was evidenced by a randomized multicenter trial conducted in 40 UC patients affected by mild to moderate distal colitis, who were randomized to four dosing cohorts of an alicaforsen enema $(0.1,0.5,2$, or $4 \mathrm{mg} / \mathrm{ml})$ or placebo, given once daily for 28 consecutive days (van Deventer et al., 2004). This therapeutic procedure resulted in the induction of clinical response in a dose-dependent way, with induction of response in $70 \%$ of alicaforsen $4 \mathrm{mg} / \mathrm{ml}$ treated patients compared to a placebo response of $28 \%$ at week 4 , which was statistically significant $(p=0.004)$. In the group treated with alicaforsen at a dosage of $2 \mathrm{mg} / \mathrm{ml}$, clinical response was evidenced in $45 \%$ of treated patients $(p=0.201)$. During the 6 months clinical follow up period, half of the patients in the placebo arm (4/8) required another medication or surgical intervention, whereas none of the patients treated with the highest dose of alicaforsen and two patients in the $2 \mathrm{mg} / \mathrm{ml}$ group required treatment escalation (van Deventer et al., 2004).

A randomized controlled trial conducted in active UC patients affected by mild to moderate left-sided colitis did not lead to a significantly different clinical outcome between the groups treated with topical application of the alicaforsen enema compared to placebo administration. The patients were randomized to five treatment arms: alicaforsen enema at a dosage of $120 \mathrm{mg}$ daily for the first 10 days of 6 weeks of treatment and then every other day thereafter; $240 \mathrm{mg}$ every other day for 6 weeks; $240 \mathrm{mg}$ daily for the first 10 days of 6 weeks of treatment and then every other day thereafter or $240 \mathrm{mg}$ daily for 6 weeks or placebo application. Primary endpoint was the Disease Activity Index (DAI) score at week 6. No significant differences were evidenced between the treatment arms and placebo (van Deventer et al., 2006). All groups demonstrated a decrease in the DAI score, but the best cohort response was identified in the group treated with daily application of $240 \mathrm{mg}$ alicaforsen enema. Clinical response at week 6 was $47 \%$ in the $240 \mathrm{mg}$ alicaforsen arm and $33 \%$ in the placebo $\operatorname{arm}(p=$ N.S.). Despite no significant differences identified for the primary endpoint clinical response, this study demonstrated that patients treated with an alicaforsen enema maintained an improved DAI score from week 18 to week 30 after commencement of therapy, compared to patients treated with placebo. The decrease in the mean DAI score compared to baseline was $51 \%$ at week 18 and $50 \%$ at week 30 in the group treated with daily application of $240 \mathrm{mg}$ alicaforsen enema, compared to $18 \%(p=0.04)$ and $11 \%$ in the placebo arm $(p=0.03)$ (van Deventer et al., 2006).

A subsequent randomized study was conducted in UC patients affected by mild to moderate distal UC, which were randomized to three treatment arms: 120 or $240 \mathrm{mg}$ alicaforsen or $4 \mathrm{~g}$ mesalazine enema, given once daily for a total of 6 weeks (Miner et al., 2006). The aim of the study was to compare the effects of alicaforsen enema administration to standard mesalazine enema therapy. The primary endpoint was DAI reduction at week 6 . No significant differences were highlighted between the treatment arms. The mean percentage reduction of the DAI score from baseline was $50 \%$ for the group treated with the mesalazine enema and $40 \%$ and $41 \%$ for the group treated with 120 and $240 \mathrm{mg}$ of the alicaforsen enema ( $p=0.27$ and 0.32 , respectively). Despite the failed difference regarding the primary endpoint, in the therapeutic arms of the alicaforsen enema the 
maintenance of clinical response was longer (128 and 146 days, respectively) in comparison to the mesalazine arm (54 days) (Miner et al., 2006). Moreover, the highest rate of mucosal healing in the $240 \mathrm{mg}$ alicaforsen group was evidenced at week 10 and was achieved by $24 \%$ of patients; in the mesalazine arm it was achieved by $17 \%$ of patients and was evidenced at week 3 and $6(p=0.06)$ (Miner et al., 2006). These two studies indicated a possible modest durable effect of alicaforsen enema application and sustained maintenance of clinical response, but nevertheless non-significance regarding the primary endpoint.

A post-hoc meta-analysis focused on the results of four phase 2 clinical studies and investigated the overall efficacy of alicaforsen enema administration in the treatment of patients with active left-sided UC and pancolitis. The authors considered for the meta-analysis three different subgroups of patients: the subgroup with distal UC with active inflammation and disease extension from $5-40 \mathrm{~cm}$; the subgroup with moderate or severe disease regardless of the extension of disease and the subgroup with both distal colitis and moderate/severe inflammation. The authors considered for the analysis the following treatment patterns: $240 \mathrm{mg}$ alicaforsen enema once daily for a duration of 6 weeks; $4 \mathrm{~g}$ mesalazine enema once daily for 6 weeks or placebo. The higher efficacy (measured as mean percentage reduction in the DAI score) of alicaforsen over placebo was statistically significant at week 6 (51.4 vs. $27.1 \% ; p=0.004)$ and week 10 (51 vs. $24.7 \% ; p=0.014)$ in patients with distal disease. At week 30, alicaforsen enema application did not demonstrate a significant effect of maintenance of clinical response in comparison to placebo therapy (Vegter et al., 2013).

In the meta-analysis, a similar clinical efficacy (measured as mean percentage reduction in the DAI score) at week 6 and 10 was evidenced between alicaforsen and mesalazine enema therapy (51.4 vs. $51.3 \%$ at week 6 and 51 vs. $41.6 \%$ at week 10 ). However, the efficacy of alicaforsen enema was more durable than that of mesalazine, after 6 weeks of treatment. At week 30 the efficacy (mean percentage reduction in the DAI score) of alicaforsen enema application resulted to be $40.1 \%$, while the efficacy of mesalazine enema was $20.6 \%(p=0.05)$ in the treated patients. Similar results as for the subgroup with distal UC were found for the remaining two other subgroups of patients (Vegter et al., 2013).

Despite the profound improvement in UC management with biological drugs, a substantial proportion of patients require surgical treatment with proctocolectomy and ileal-pouch-anal anastomosis (IPAA) in the course of disease, in particular for severe flares of active disease, refractory to available medical therapies or due to the diagnosis of non-resectable colonic dysplasia. Onset of acute or chronic pouchitis is one of the most frequently occurring post-operative complications that patients experience and almost half of them present with this kind of problem within 5 years after the time of surgery (Tiainen and Matikainen, 1999). Alicaforsen could represent a novel therapeutic option for this hard to treat clinical problem, as indicated by conducted studies.

A first open-label uncontrolled study conducted in 12 patients affected by chronic pouchitis figured out a statistical significant reduction of the Pouch-Disease-Activity-Index (PDAI), which was 11.42 at baseline and 6.83 at week $6(p=0.001)$ and also of the
PDAI endoscopic sub-score at week 6, which was 3.75 at baseline and 2.25 at week $6(p=0.0117)$ after daily topical administration of alicaforsen at a dosage of $240 \mathrm{mg}$ for 6 weeks (Miner et al., 2004; McConnell et al., 2009). A phase III randomized trial conducted in patients affected by refractory pouchitis has been recently completed (Fiorino et al., 2011; EPG Health, 2018).

The main findings regarding the above mentioned clinical trials can be found in Table 1 .

\section{MONGERSEN}

Immune homeostasis in the intestinal mucosa plays a fundamental role in preventing inflammatory immune responses in IBD (MacDonald and Monteleone, 2005; MacDonald et al., 2011). One of the most important cytokines that mediate a regulatory mucosal immune response is Transforming Growth Factor $\beta$ (TGF $\beta)$. This cytokine has been implicated in the function of regulatory $\mathrm{T}$ ( $\mathrm{T}$ reg) cells that mediate suppression of inflammatory responses, as evidenced in mice models of colitis (Powrie et al., 1996). Different studies figured out a greater level of regulatory $\mathrm{T}$ cells in the inflamed mucosa of IBD patients than in healthy controls, thereby inducing subsequent studies for the analysis of $\mathrm{T}$ reg cells in the tissue of IBD patients (Monteleone et al., 2001).

A study conducted in mice models of colitis demonstrated increased TGF $\beta$ levels in the inflamed tissue of colitic mice, indicating that a blockade of TGF $\beta$ signaling transduction by counter-regulatory proteins overexpressed during the active state of inflammation might be involved to suppress its antiinflammatory function (Boirivant et al., 2006). This finding has been the first step toward the discovery of Mothers against decapentaplegic homolog 7 (Smad7) that has an inhibitory role within the TGF $\beta$ signaling cascade. This intracellular signaling molecule is an inhibitor of TGF $\beta$ signaling, as it can bind to the TGF $\beta$ receptor thereby inhibiting phosphorylation of downstream signaling molecules such as Smad2 and Smad3, whose activation mediates TGF $\beta$ signal transduction.

First studies figured out a heightened expression of Smad7 in the mucosal intestinal compartment of IBD patients (Monteleone et al., 2001). In contrast, high expression of phosphorylated Smad3 was seen in the normal intestinal mucosa (Monteleone et al., 2001). The same study showed an increased response of intestinal mononuclear cells to TGF $\beta$ after the administration of a Smad7 ASO, which restored the phosphorylation of Smad3. These findings demonstrate that Smad7 blockade by a Smad7 ASO enabled TGF $\beta$ to inhibit the function of pro-inflammatory intestinal cells.

A subsequent phase I open-label study of an ASO against Smad7 (GED0301) was conducted in CD patients with steroid-dependent/resistant disease. Fifteen $\mathrm{CD}$ patients were randomized to receive one of the three treatment dosages of oral GED0301 (40, 80, or $160 \mathrm{mg})$ once daily for 7 consecutive days. The drug was well-tolerated. Oral administration of GED0301 (mongersen) led to the reduction of pro-inflammatory C-C Chemokine Receptor 9 (CCR9)-positive $\mathrm{T}$ cells in the bloodstream. This study showed a good safety and tolerability profile of the studied substance (Monteleone et al., 2012). Since TGF $\beta$ has been described to induce the 


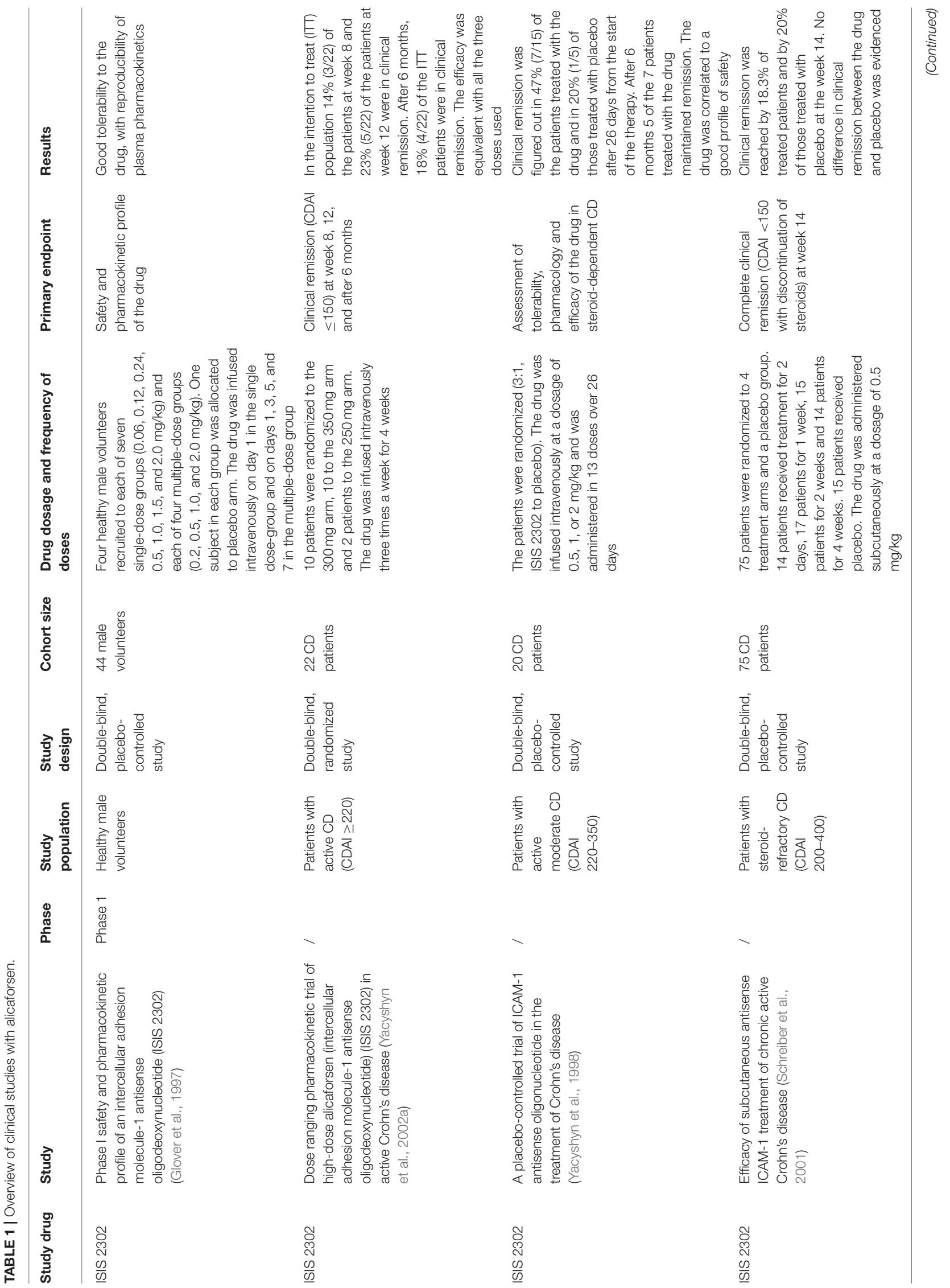




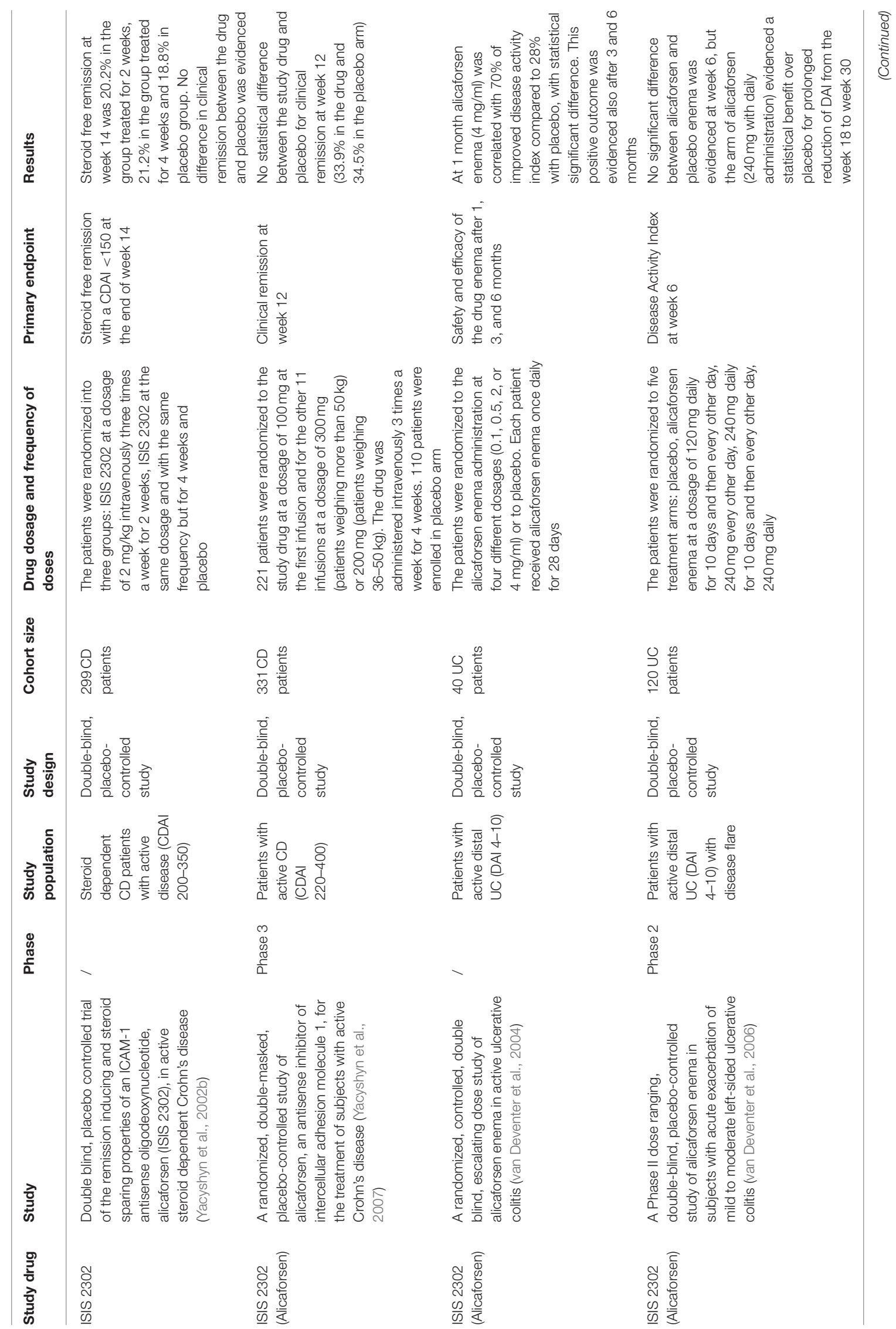




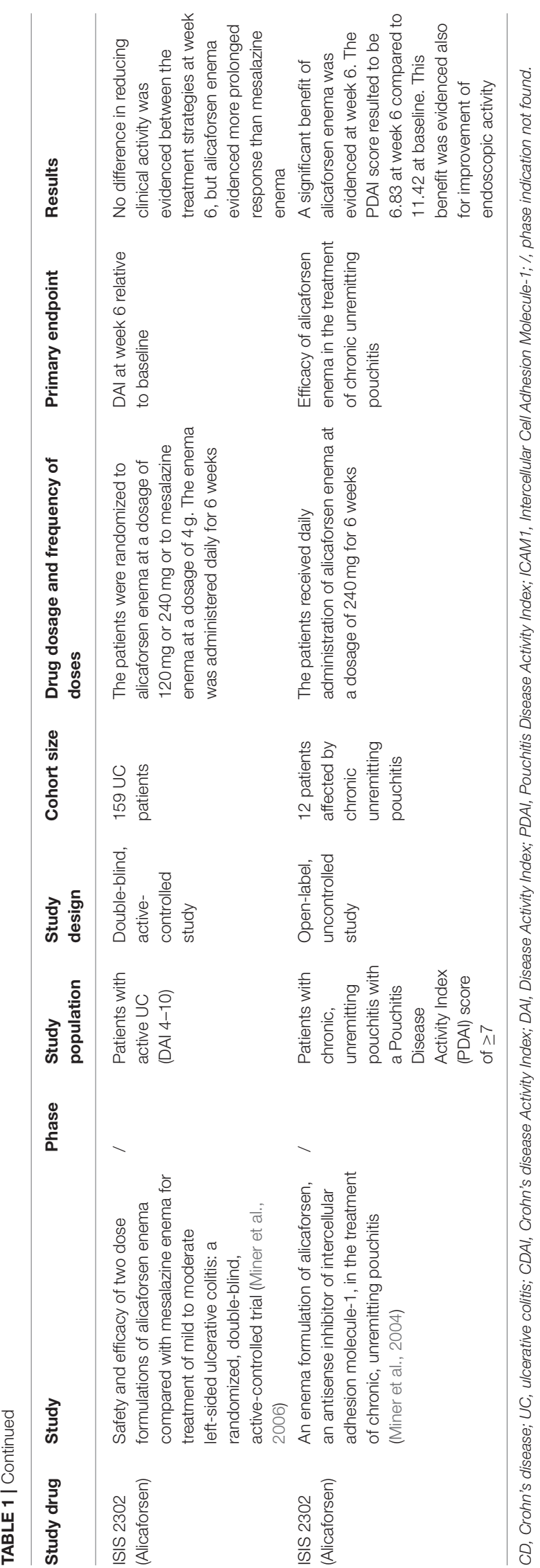

profibrogenetic response of fibroblasts, patients were monitored for 6 months with intestinal ultrasonography, not showing signs of intestinal stenosis. Moreover, half of the patients maintained remission during the 6 months follow up period (Zorzi et al., 2012).

Afterwards, a randomized, double-blind, phase 2 study was conducted in $\mathrm{CD}$ patients with inflammatory lesions in the terminal ileum and/or right colon, with steroiddependence/resistance, randomized to three different daily oral drug doses (10,40, or $160 \mathrm{mg}$ of mongersen or placebo) for 2 weeks. The primary outcome was clinical remission at day 15 , with maintenance of remission for at least 2 weeks. Clinical remission was not significantly different between the patients in the $10 \mathrm{mg}$ mongersen group and placebo (12 vs. $10 \% ; p=$ N.S.); however clinical remission was reached by $55 \%$ and $65 \%$ of patients in the 40 and $160 \mathrm{mg}$ mongersen group, as compared to $10 \%$ in the placebo group $(p<0.001)$. The drug showed a good safety and tolerability profile (Monteleone et al., 2015).

A following study demonstrated efficacy of GED0301 in inducing both clinical and endoscopic response in a study group of $63 \mathrm{CD}$ patients. The patients were randomized to three treatment groups $(4,8$, or 12 weeks of treatment with oral GED0301 at a dose of $160 \mathrm{mg} /$ day). $37 \%$ of patients had an endoscopic response, defined as $\geq 25 \%$ reduction in Simple Endoscopic Score for Crohn's disease (SES-CD), at week 12, with a substantial proportion of patients in clinical remission at the same time point (32\% in the group of 4 weeks of treatment, 35 and $48 \%$, respectively in the group of 8 and 12 weeks of treatment) (Feagan et al., 2018). This study however lacked a placebo control group.

Despite these promising results, a recently conducted phase 3 study was stopped following the finding of non-effectiveness of the studied drug. No safety findings were reported (Bevivino et al., 2018; White et al., 2018).

The main findings regarding the above mentioned clinical trials can be found in Table 2 .

\section{NFkB ASO}

Preclinical studies, conducted in murine models of colitis, demonstrated the efficacy of an ASO against the p65 subunit of the transcription factor Nuclear Factor Kappa B (NFkB) (Neurath et al., 1996; Murano et al., 2000). This transcription factor mediates a key role in the pro-inflammatory response of immune-mediated disorders (Zhang et al., 2017).

A preclinical study evidenced an upregulation of p65 expression in macrophages located in the Lamina propria of patients affected by $\mathrm{CD}$. The authors demonstrated the efficacy of a human p65 ASO to reduce the production of pro-inflammatory cytokines by these cells (Neurath et al., 1996). Another study conducted in a murine model of colitis demonstrated a downregulation of chronic inflammation- induced intestinal fibrosis by the p65 ASO (Lawrance et al., 2003).

Despite these promising results, no clinical study has been published so far regarding the use of this therapeutic strategy in IBD patients (Marafini and Monteleone, 2018). 


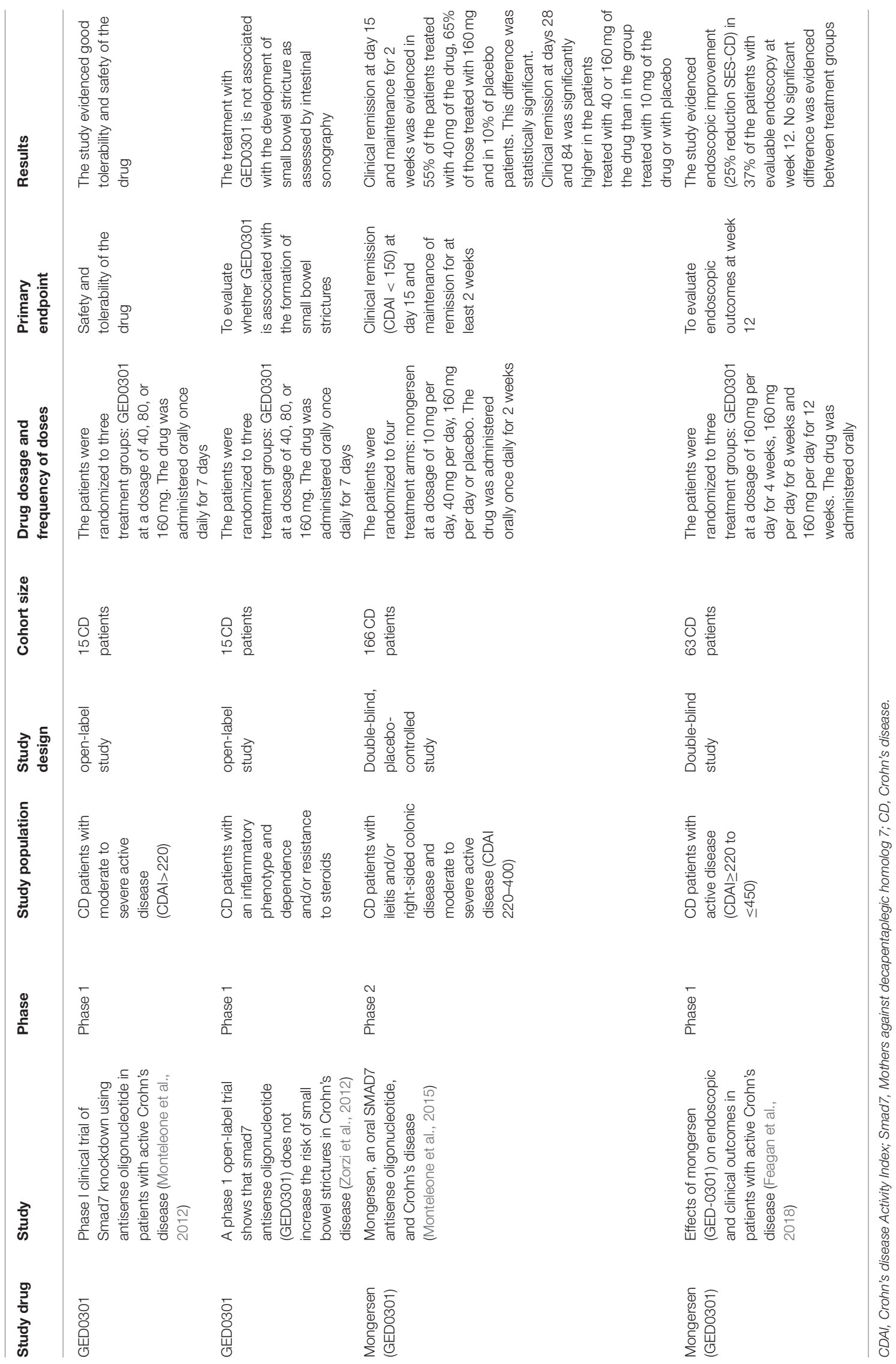




\section{COBITOLIMOD}

Cobitolimod (formerly referred to as DIMS0150) is a singlestranded oligonucleotide that is recognized by the Toll-like Receptor 9 (TLR9) and represents a possible promising novel therapy for UC patients. The altered response of intestinal immune cells to the commensal bacterial flora has been considered to be one of the pivotal pathogenic mechanisms in UC (Strober et al., 2007). The protective immune cell response plays the counterpart action against the over activation of the mucosal immune system (Neurath, 2014). Toll-like receptors (TLRs) belong to pattern recognition receptors (PRRs), which mediate the recognition process of self-antigens from foreignantigens by the host. These receptors can recognize the pathogen associated molecular patterns (PAMPs) and are implicated in the first defensive innate immune response against luminal pathogens, but can also induce mechanisms of cellular and mucosal repair (Lee et al., 2006). TLR9 is a member of the TLR family and recognizes bacterial DNA, but also viral DNA (e.g., Cytomegalovirus DNA). This receptor in particular recognizes bacterial Cytosine Guanine (CpG) dinucleotides motifs (Hemmi et al., 2000).

A study in the murine model of Salmonella typhimurium infection figured out that the activation of TLR9 maintained the homeostasis of intestinal mucosal cells, demonstrating that disruption of TLR9 signaling could result in augmented inflammation and worsening of intestinal injury (Li et al., 2017).

Cobitolimod is a 19 base single-strand oligonucleotide which mimics bacterial DNA as its CpG dinucleotide sequences are recognized by the TLR9 expressed by different immune cells, thereby mediating anti-inflammatory effects. In preclinical studies in murine models of colitis, administration of the TLR9 oligonucleotide agonist suppressed the severity of colitis in RAG-/- mice. The type I Interferon (IFN $\alpha / \beta$ ) was induced by TLR9 activation and mediated anti-inflammatory responses (Katakura et al., 2005). In another preclinical study conducted in the experimental DSS model and spontaneous colitis mice, administration of $\mathrm{CpG}$ oligonucleotides improved clinical, biochemical and histologic activity of colonic inflammation (Rachmilewitz et al., 2002).

A study published in 2013 considered the possible efficacy of DIMS0150 in treating UC patients who had been considered as treatment failures with indication for colectomy. Seven patients received a single dose of topical DIMS0150 (30 mg) and one patient three doses with an interval of 4 weeks in between. The study drug was applied during colonoscopy with a spray catheter in the upper descending colon or the transverse colon. Efficacy was recorded as an improvement of the DAI score and of endoscopic and histological activity at week 12. Clinical response was found in all patients 1 week after single endoscopic administration of the drug. After 12 weeks, 82\% of patients had a clinical response while $71 \%$ were in clinical remission. In the 2-year follow up one patient needed colectomy (Musch et al., 2013).

A non-interventional pilot study analyzed the transcripts of 34 steroid response genes by polymerase chain reaction (PCR) in the blood derived peripheral mononuclear cells
(PBMCs) of steroid refractory UC patients, after their incubation with DIMS0150 $(25$ or $100 \mu \mathrm{M})$ in the presence of Dexamethasone. The authors evidenced that addition of DIMS0150 to steroid treatment produced a significant enhancement of mRNA levels of three steroid response genes (CD163, TSP-1, and IL-1RII) and suggested to consider these genes as potential biomarkers of response to the study drug. This study highlighted the potential effect of DIMS0150 to restore steroid sensitivity in steroid refractory UC patients (Kuznetsov et al., 2014).

After these findings a randomized, double-blind, placebocontrolled trial (COLLECT study) was conducted in 131 patients affected by moderate to severe UC. Patients were randomized to receive two topical endoscopic administrations of cobitolimod (DIMS0150) at a dosage of $30 \mathrm{mg}$ at baseline and week 4 or respective placebo application. The administration was done proximally to the site of mucosal inflammation, or in the transverse colon in the event of pancolitis, using a spray catheter during endoscopy (Atreya et al., 2016). There was no statistical difference in the primary endpoint clinical remission, defined as a CAI score of $\leq 4$ at week 12 , which was recorded in $44.4 \%$ of cobitolimod treated patients and in $46.5 \%$ of those treated with placebo (Atreya et al., 2016). However, symptomatic remission, which was defined as the absence of blood in stool and a weekly frequency of $<35$ stools, was shown in a larger proportion of patients treated with the drug compared to those treated with placebo $(32.1 \%$ in the cobitolimod group vs. $14 \%$ in the placebo group at week $4(p=0.02)$ and 44.4 vs. $27.9 \%$, respectively at week $8(p=0.06)$. Mucosal healing at week 4 was also achieved by more cobitolimod treated patients compared to the placebo group, but missed statistical significance (34.6 vs. $18.6 \% ; p=0.09$ ). Histological improvement, defined as a Geboes score of $0-2$, was evident in $30.9 \%$ of the cobitolimod treated vs. $9.3 \%$ of the placebo treated patients $(p=0.007)$. The combination of clinical and endoscopic remission could be observed in $21 \%$ of cobitolimod treated patients vs. $4.7 \%$ of patients on placebo ( $p=$ 0.021) at week 4 (Atreya et al., 2016).

A recent post-hoc analysis, based on data from the COLLECT study, has shown that the clinical efficacy of the drug is significant if patient-reported-outcomes (PRO) were considered, as the investigated outcome measure. Symptomatic remission was studied in 104 patients based on their e-diary records and was defined as the absence of blood in stool and a mean daily stool frequency $<4$ (Atreya et al., 2018). Symptomatic remission was found at week 4 in $17.1 \%$ of patients treated with cobitolimod compared to $5.9 \%$ of patients treated with placebo $(p=0.13)$ and, respectively, in 35.7 and $17.6 \%(p=0.07)$ at week 8 and in 38.6 and $17.6 \%(p=0.04)$ at week 12 (Atreya et al., 2018).

BL7040 (Monarsen) is an orally applied oligonucleotide that modulates the TLR9 and it was investigated in a prospective multicenter phase 2 study in patients with moderately active UC at doses of $12 \mathrm{mg}$ once daily for 3 weeks followed by $40 \mathrm{mg}$ once daily for 2 weeks. The primary endpoint was the proportion of patients with clinical response at the end of 5 weeks of treatment. Clinical response was defined by a decrease of at least three points and $30 \%$ reduction of the Mayo score compared to baseline. Half of the patients $(8 / 16)$ achieved clinical response at the end of the 
course of treatment, with a good tolerability profile of the drug (Dotan et al., 2016).

Altogether, agonists of the Toll-like receptor-9 appeared safe and well-tolerated in moderate to severe UC patients and could represent a novel promising therapeutic option for the management of UC patients.

Currently, a phase 2 study (CONDUCT) of different doses and different administration intervals of cobitolimod in an enema formulation is tested in patients affected by moderate to severe $\mathrm{UC}^{1}$.

The main findings regarding the above mentioned clinical trials can be found in Table 3 .

\section{GATA3 DNAzyme}

The adaptive immune response and inappropriate production of pro-inflammatory cytokines have an important pathogenic role in IBD pathogenesis. CD is characterized by a prevalence of $\mathrm{T}$ helper 1 (Th1) cytokines such as Interferon gamma (IFN $\gamma$ ) and TNF, whereas UC is marked by a of more Th2 oriented cytokine profile, characterized by IL4, IL5, and IL13 (Fuss et al., 1996, 2004). However, these subsets of $\mathrm{T}$ cells are not the only responsible cells for the inflammatory response in IBD. Th17 cells are another lymphocyte subpopulation which has a major role in intestinal inflammation in both CD and UC (Giuffrida et al., 2018). A recent published review revealed also the important role of other lymphocyte subsets in mucosal inflammation (Giuffrida et al., 2018). Importantly, Th9 cells and IL9 have also been described to play a pivotal role in the pathogenesis of UC (Nalleweg et al., 2015; Weigmann and Neurath, 2017).

The GATA3 specific DNAzyme (SB010) is an oligonucleotide which can mediate the cleavage of the mRNA of the transcription factor GATA3 and its possible therapeutic usage in human diseases was first investigated in patients affected by allergic asthma. A double-blind placebo-controlled study randomized 40 patients, affected by allergic asthma, to receive $10 \mathrm{mg}$ of SB010 or placebo. The drug was administered by inhalation once daily for 28 days. Treatment with SB010 was found to be effective in attenuating the late and early asthmatic responses to allergen provocation; thereby the drug induced also a significant reduction of IL5 blood levels (Krug et al., 2015).

The Th2 response is mediated by the transcription factor GATA3, which has proven to be over-expressed in the colonic mucosa of UC patients (Ho et al., 2009; Ohtani et al., 2010). This transcription factor is not only linked to Th2 cell responses, but also plays an important role in regulating the differentiation of Th9 lymphocytes (Wan, 2014).

A study conducted with intestinal biopsies of UC patients as well as murine models of colitis showed a correlation between the expression of the transcription factor GATA3 and the production of inflammatory Th2 and Th9 related cytokines (Popp et al., 2016). Conditional GATA3 deficiency in T cells prevented experimental colitis in mice. Intrarectal administration of a GATA3 specific DNAzyme (hgd40) significantly ameliorated colitis in oxazolone and 2,4,6-trinitrobenzene sulfonic acid

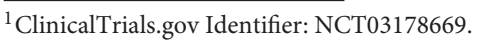

(TNBS)-mediated colitis models (Popp et al., 2016). The authors also demonstrated that the inhibition of GATA3 transcription by hgd40 was able to ameliorate colitis also in TNF receptor (TNFR) double-knockout mice. This result evidenced the efficacy of the experimental drug in reducing colitis in mice, independently of the presence of TNF (Popp et al., 2016).

These results underline the important role of GATA3 in the inflammatory response in UC and suggest a possible future role of the GATA3 DNAzyme in the therapy of UC patients.

A study of this novel drug as an enema formulation (SB012, SECURE study) in patients with moderate to severe UC has recently been completed (NCT02129439) ${ }^{2}$.

\section{STNM01: AN OLIGONUCLEOTIDE AGAINST CARBOHYDRATE SULFOTRANSFERASE 15}

IBD pathogenesis is not only connected to an active acute and chronic inflammatory response but also to structural damage, with matrix remodeling and tissue fibrosis, which can take place independently of the inflammatory activity (Suzuki and Yoneyama, 2017). Approximately one third of patients with $\mathrm{CD}$ and 5\% of those with UC are diagnosed with fibrotic stenosis in the clinical course (Rieder et al., 2013; de Bruyn et al., 2015). There are no specific therapies for the management of fibrotic intestinal remodeling, induced by the over activation of stromal cells during chronic inflammation. Invasive treatment (endoscopic dilation and/or surgical treatment) represent the inevitable final management step of this complication.

Carbohydrate sulfotransferase 15 (CHST15) is an intracellular enzyme that mediates the biosynthesis of sulfated matrix glycosaminoglycans (GAG) which can induce fibrotic reactions in IBD patients.

STNM01 is a novel double-strand RNA oligonucleotide that selectively blocks the expression of CHST15 mRNA and can inhibit the excessive production of glycosaminoglycans in the colon by fibroblasts (Suzuki et al., 2016).

For this reason an endoscopic approach of drug delivery through submucosal injection, to directly target the gut lesion, was established in mice in 2016 (Suzuki et al., 2016). CHST15 siRNA or negative control siRNA were endoscopically administered by submucosal injection at day 6 in DSSmediated colitis models. The mice were sacrificed at day 19 to evaluate the effect of the experimental drug. CHST15 siRNA reduced CHST15 mRNA in the colon of treated mice and significantly ameliorated endoscopic and histologic disease activity (Suzuki et al., 2016).

A subsequent published randomized placebo-controlled trial evaluated the safety of STNM01 in CD patients whose mucosal ulcerative lesions were refractory to conventional therapy. Eighteen $\mathrm{CD}$ patients were randomized to receive a single endoscopic submucosal injection of STNM01 (2.5,

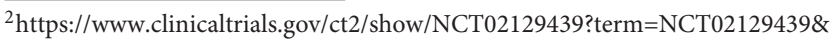
rank=1 


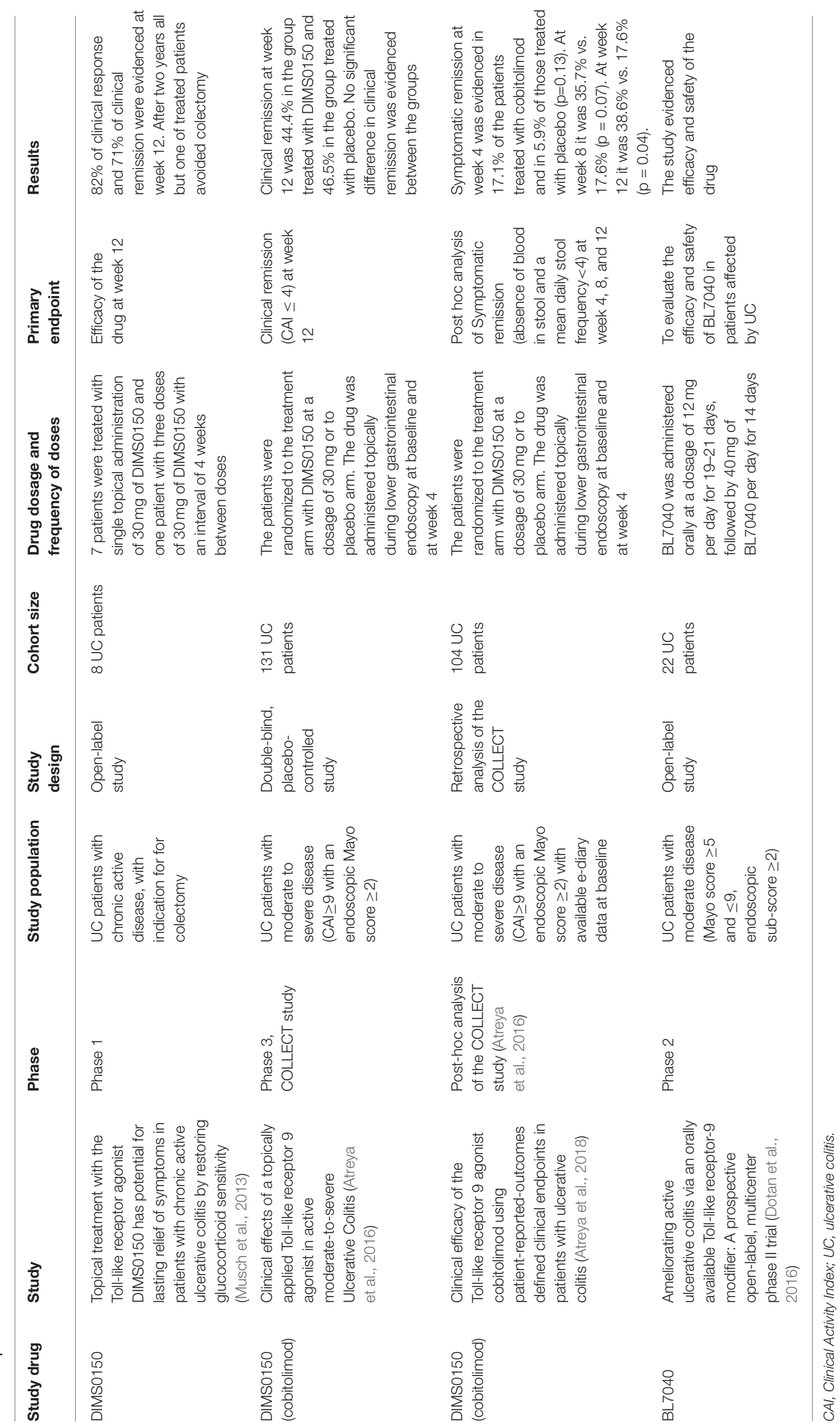




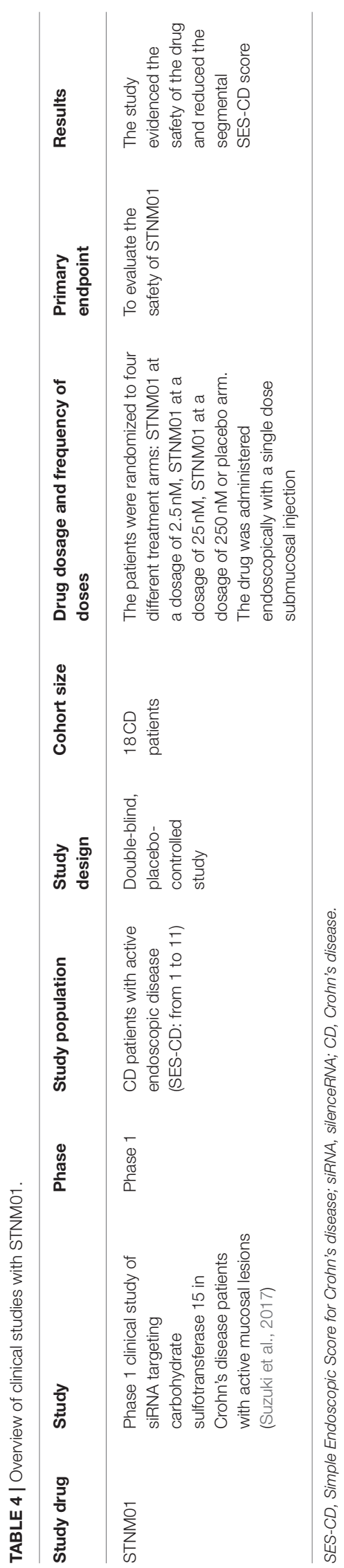

25 , or $250 \mathrm{nM}$ ) or placebo. Each dose was administered to eight sites directly surrounding the biggest ulcerative lesion evidenced by total colonoscopy. STNM01 was able to reduce the segmental SES-CD score at day 30 when compared to the placebo arm and was also able to induce a reduced extension of fibrosis, documented by histological analyses. The experimental drug also showed a good safety profile (Suzuki et al., 2017).

A phase 2 clinical trial in UC patients affected by refractory left-sided UC has recently been completed. The patients were randomized to submucosal injections of STNM01 or placebo in the last $35 \mathrm{~cm}$ of the colon.

The main findings regarding the above mentioned clinical trials can be found in Table 4 .

\section{CONCLUSIONS}

In this review, we focused on recent and past approaches to test the therapeutic efficacy of oligonucleotide based therapies in IBD.

The combining mechanistic mode of oligonucleotide based therapeutics is a targeted action on specific pro-inflammatory molecules, which are over activated in IBD patients and contribute significantly to disease pathogenesis. The proposed high selectivity of the agents is derived from its mode of action, that aims to specifically block certain inflammatory molecular patterns, without a general systemic effect on other molecular targets. It would be important for each oligonucleotide to present more data regarding its specific mode of molecular action. Ideally, interaction with the proposed molecular target should be presented. Overall, the good tolerance and safety profile has allowed increasing development of this therapeutic approach in IBD clinical research and trials.

This new treatment strategy has the potential to address the main concern of a safe long-term therapy for IBD patients. Moreover, efficacious therapy could be prolonged as lasting maintenance therapy, as there is no risk for secondary loss-ofresponse due to the formation of anti-drug antibodies, which is one of the main reasons for limited long-term efficacy of biological drugs (Atreya and Neurath, 2018).

The above-mentioned properties and selectivity of oligonucleotides could respond to the dire need for a safe and efficacious long-term therapy. The numerous clinical trials conducted so far have shown the possibility of oligonucleotide treatment to match the target of safety and efficacy, but till now no oligonucleotide based therapy has been approved for clinical practice in the treatment of IBD patients and we still await successful late-stage clinical studies that demonstrate their efficaciousness.

\section{AUTHOR CONTRIBUTIONS}

PS wrote the manuscript. HS, GM, and MN assessed the articles and their relevance to the above topics. RA supervised and drafted the manuscript and is the corresponding author. 


\section{FUNDING}

Funding by the German Research Foundation: DFG-CRC1181 Project C02 (RA) and DFG-SFB/TRR241 Project No. C02 (RA). The Heisenberg Professorship of RA is funded by the DFG.

\section{REFERENCES}

Aboul-Fadl, T. (2005). Antisense oligonucleotides: the state of the art. Curr. Med. Chem. 12, 2193-2214. doi: 10.2174/0929867054864859

Atreya, R., Bloom, S., Scaldaferri, F., Gerardi, V., Admyre, C., Karlsson, Å., et al. (2016). Clinical effects of a topically applied Toll-like receptor 9 agonist in active moderate-to-severe Ulcerative Colitis. J. Crohn Colitis 10, 1294-1302. doi: 10.1093/ecco-jcc/jjw103

Atreya, R., and Neurath, M. F. (2018). Mechanisms of molecular resistance and predictors of response to biological therapy in inflammatory bowel disease. Lancet Gastroenterol. Hepatol. 3, 790-802. doi: 10.1016/S2468-1253(18)30265-6

Atreya, R., Reinisch, W., Peyrin-Biroulet, L., Scaldaferri, F., Admyre, C., Knittel, T., et al. (2018). Clinical efficacy of the Toll-like receptor 9 agonist cobitolimod using patient-reported-outcomes defined clinical endpoints in patients with ulcerative colitis. Dig. Liver Dis. 50, 1019-1029. doi: 10.1016/j.dld.2018.06.010

Bevivino, G., Sedda, S., Marafini, I., and Monteleone, G. (2018). Oligonucleotidebased therapies for inflammatory bowel disease. BioDrugs 32, 331-338. doi: 10.1007/s40259-018-0286-1

Boirivant, M., Pallone, F., Di Giacinto, C., Fina, D., Monteleone, I., Marinaro, M., et al. (2006). Inhibition of Smad7 with a specific antisense oligonucleotide facilitates TGF- $\beta 1-$ mediated suppression of colitis. Gastroenterology 131, 1786-1798. doi: 10.1053/j.gastro.2006.09.016

Burns, R. C., Rivera-Nieves, J., Moskaluk, C. A., Matsumoto, S., Cominelli, F., and Ley, K. (2001). Antibody blockade of ICAM-1 and VCAM-1 ameliorates inflammation in the SAMP-1/Yit adoptive transfer model of Crohn's disease in mice. Gastroenterology 121, 1428-1436. doi: 10.1053/gast.2001. 29568

Crooke, S. T. (2004). Progress in antisense technology. Annu. Rev. Med. 55, 61-95. doi: 10.1146/annurev.med.55.091902.104408

de Bruyn, J. R., Meijer, S. L., Wildenberg, M. E., Bemelman, W. A., van den Brink, G. R., and D' Haens, G. R. (2015). Development of fibrosis in acute and longstanding ulcerative colitis. J. Crohn Colitis 9, 966-972. doi: 10.1093/ecco-jcc/jjv133

Dotan, I., Levy-Nissenbaum, E., Chowers, Y., Fich, A., Israeli, E., Adar, T., et al. (2016). Ameliorating active ulcerative colitis via an orally available toll-like receptor-9 modifier: a prospective open-label, multicenter phase II trial. Dig. Dis. Sci. 61, 3246-3254. doi: 10.1007/s10620-016-4276-1

EPG Health. (2018). Randomized Study of Topical Alicaforsen Enema in Antibiotic Refractory Pouchitis. Available online at: https://clinicaltrials.gov/ct2/ show/record/NCT02525523?term=alicaforsen\&rank=1 (accessed November 1, 2014).

Feagan, B. G., Sands, B. E., Rossiter, G., Li, X., Usiskin, K., Zhan, X., et al. (2018). Effects of mongersen (GED-0301) on endoscopic and clinical outcomes in patients with active Crohn's disease. Gastroenterology 154, 61-64.e6. doi: 10.1053/j.gastro.2017.08.035

Fiorino, G., Cesarini, M., and Danese, S. (2011). Biological therapy for ulcerative colitis: what is after anti-TNF. Current Drug Targets 12, 1433-1439. doi: $10.2174 / 138945011796818225$

Fuss, I. J., Heller, F., Boirivant, M., Leon, F., Yoshida, M., Fichtner-Feigl, S., et al. (2004). Nonclassical CD1d-restricted NK T cells that produce IL-13 characterize an atypical Th2 response in ulcerative colitis. J. Clin. Invest. 113, 1490-1497. doi: 10.1172/JCI19836

Fuss, I. J., Neurath, M., Boirivant, M., Klein, J. S., de la Motte, C., Strong, S. A., et al. (1996). Disparate CD4 ${ }^{+}$lamina propria (LP) lymphokine secretion profiles in inflammatory bowel disease. Crohn's disease LP cells manifest increased secretion of IFN-gamma, whereas ulcerative colitis LP cells manifest increased secretion of IL-5. J. Immunol. 157, 1261-1270.

\section{SUPPLEMENTARY MATERIAL}

The Supplementary Material for this article can be found online at: https://www.frontiersin.org/articles/10.3389/fphar. 2019.00314/full\#supplementary-material

Gewirtz, A. T., and Sitaraman, S. (2001). Alicaforsen. Isis pharmaceuticals. Curr Opin. Invest. Drugs 2, 1401-1406.

Giuffrida, P., Corazza, G. R., and Di Sabatino, A. (2018). Old and new lymphocyte players in inflammatory bowel disease. Dig. Dis. Sci. 63, 277-288. doi: 10.1007/s10620-017-4892-4

Glover, J. M., Leeds, J. M., Mant, T. G., Amin, D., Kisner, D. L., Zuckerman, J. E., et al. (1997). Phase I safety and pharmacokinetic profile of an intercellular adhesion molecule-1 antisense oligodeoxynucleotide (ISIS 2302). J. Pharmacol. Exp. Ther. 282, 1173-1180.

Hamamoto, N., Maemura, K., Hirata, I., Murano, M., Sasaki, S., and Katsu, K. (1999). Inhibition of dextran sulphate sodium (DSS)-induced colitis in mice by intracolonically administered antibodies against adhesion molecules endothelial leucocyte adhesion molecule-1 (ELAM-1) or intercellular adhesion molecule-1 (ICAM-1). Clin. Exp. Immunol. 117, 462-468. doi: 10.1046/j.1365-2249.1999.00985.x

Hemmi, H., Takeuchi, O., Kawai, T., Kaisho, T., Sato, S., Sanjo, H., et al. (2000). A Toll-like receptor recognizes bacterial DNA. Nature 408, 740-745. doi: $10.1038 / 35047123$

Ho, I. C., Tai, T. S., and Pai, S. Y. (2009). GATA3 and the T-cell lineage: essential functions before and after Thelper-2-cell differentiation. Nat. Rev. Immunol. 9, 125-135. doi: 10.1038/nri2476

Jones, S. C., Banks, R. E., Haidar, A., Gearing, A. J., Hemingway, I. K., Ibbotson, S. H., et al. (1995). Adhesion molecules in inflammatory bowel disease. Gut 36, 724-730. doi: 10.1136/gut.36.5.724

Kaplan, G. G., and Ng, S. C. (2017). Understanding and preventing the global increase of inflammatory bowel disease. Gastroenterology 152, 313-321. doi: 10.1053/j.gastro.2016.10.020

Katakura, K., Lee, J., Rachmilewitz, D., Li, G., Eckmann, L., and Raz, E. (2005). Toll-like receptor 9-induced type I IFN protects mice from experimental colitis. J. Clin. Invest. 115, 695-702. doi: 10.1172/JCI22996

Krug, N., Hohlfeld, J. M., Kirsten, A. M., Kornmann, O., Beeh, K. M. Kappeler, D., et al. (2015). Allergen-induced asthmatic responses modified by a GATA3-specific DNAzyme. N. Engl. J. Med. 372, 1987-1995. doi: 10.1056/NEJMoa1411776

Kuznetsov, N. V., Zargari, A., Gielen, A. W., von Stein, O. D., Musch, E., Befrits, R., et al. (2014). Biomarkers can predict potential clinical responders to DIMS0150 a toll-like receptor 9 agonist in ulcerative colitis patients. BMC Gastroenterol. 14:79. doi: 10.1186/1471-230X-14-79

Lawrance, I. C., Wu, F., Leite, A. Z., Willis, J., West, G. A., Fiocchi, C., et al. (2003). A murine model of chronic inflammation-induced intestinal fibrosis down-regulated by antisense NF-kappa B. Gastroenterology 125, 1750-1761. doi: 10.1053/j.gastro.2003.08.027

Lee, J., Mo, J. H., Katakura, K., Alkalay, I., Rucker, A. N., Liu, Y. T., et al. (2006). Maintenance of colonic homeostasis by distinctive apical TLR9 signalling in intestinal epithelial cells. Nat. Cell. Biol. 8, 1327-1336. doi: 10.1038/ncb1500

Li, Y., Liu, M., Zuo, Z., Liu, J., Yu, X., Guan, Y., et al. (2017). TLR9 regulates the NF- $\mathrm{B}$-NLRP3-IL-1 $\beta$ pathway negatively in Salmonella-induced NKG2D-mediated intestinal inflammation. J. Immunol. 199, 761-773. doi: 10.4049/jimmunol.1601416

Lobaton, T., Vermeire, S., Van Assche, G., and Rutgeerts, P. (2014). Anti-adhesion therapies for inflammatory bowel disease. Aliment. Pharmacol. Ther. 39, 579-594. doi: 10.1111/apt.12639

Maaser, C., Sturm, A., Vavricka, S. R., Kucharzik, T., Fiorino, G., Annese, V., et al. (2019). European Crohn's and Colitis Organisation [ECCO] and the European Society of Gastrointestinal and Abdominal Radiology [ESGAR]. ECCO-ESGAR Guideline for Diagnostic Assessment in IBD Part 1: Initial diagnosis, monitoring of known IBD, detection of complications. J Crohns Colitis. 13, 144-164. doi: 10.1093/ecco-jcc/jjy113 
MacDonald, T. T., and Monteleone, G. (2005). Immunity, inflammation, and allergy in the gut. Science 307, 1920-1925. doi: 10.1126/science. 1106442

MacDonald, T. T., Monteleone, I., Fantini, M. C., and Monteleone, G. (2011). Regulation of homeostasis and inflammation in the intestine. Gastroenterology 140, 1768-1775. doi: 10.1053/j.gastro.2011.02.047

Maksymowych, W. P., Blackburn, W. D., Tami, J. A., and Shanahan, W. R. Jr. (2002). A randomized, placebo controlled trial of an antisense oligodeoxynucleotide to intercellular adhesion molecule-1 in the treatment of severe rheumatoid arthritis. J. Rheumatol. 29, 447-453.

Marafini, I., and Monteleone, G. (2018). Inflammatory bowel disease: new therapies from antisense oligonucleotides. Ann. Med. 16, 1-22. doi: 10.1080/07853890.2018.1490025

McConnell, E. L., Liu, F., and Basit, A. W. (2009). Colonic treatments and targets: issues and opportunities. J. Drug Targeting 5, 335-363. doi: $10.1080 / 10611860902839502$

Miner, P., Wedel, M., Bane, B., and Bradley, J. (2004). An enema formulation of alicaforsen, an antisense inhibitor of intercellular adhesion molecule-1, in the treatment of chronic, unremitting pouchitis. Aliment. Pharmacol. Ther. 19, 281-286. doi: 10.1111/j.1365-2036.2004.01863.x

Miner, P. B. Jr, Wedel, M. K., Xia, S., and Baker, B. F. (2006). Safety and efficacy of two dose formulations of alicaforsen enema compared with mesalazine enema for treatment of mild to moderate left-sided ulcerative colitis: a randomized, double-blind, active-controlled trial. Aliment. Pharmacol. Ther. 23, 1403-1413. doi: 10.1111/j.1365-2036.2006.02837.x

Monteleone, G., Fantini, M. C., Onali, S., Zorzi, F., Sancesario, G., Bernardini, S., et al. (2012). Phase I clinical trial of Smad7 knockdown using antisense oligonucleotide in patients with active Crohn's disease. Mol. Ther. 20, 870-876. doi: $10.1038 / \mathrm{mt} .2011 .290$

Monteleone, G., Kumberova, A., Croft, N. M., McKenzie, C., Steer, H. W., and MacDonald, T. T. (2001). Blocking Smad7 restores TGF-betal signaling in chronic inflammatory bowel disease. J. Clin. Investig. 108, 601-609. doi: $10.1172 /$ JCI12821

Monteleone, G., Neurath, M. F., Ardizzone, S., Di Sabatino, A., Fantini, M. C., Castiglione, F., et al. (2015). Mongersen, an oral Smad7 antisense oligonucleotide, and Crohn's disease. N. Engl. J. Med. 372:2461. doi: $10.1056 /$ nejmc1504845

Mosli, M. H., Rivera-Nieves, J., and Feagan, B. G. (2014). T-cell trafficking and anti-adhesion strategies in inflammatory bowel disease: current and future prospects. Drugs 74, 297-311. doi: 10.1007/s40265-013-0176-2

Murano, M., Maemura, K., Hirata, I., Toshina, K., Nishikawa, T., Hamamoto, N., et al. (2000). Therapeutic effect of intracolonically administered nuclear factor kappa B (p65) antisense oligonucleotide on mouse dextran sulphate sodium (DSS)-induced colitis. Clin. Exp. Immunol. 120, 51-58. doi: 10.1046/j.1365-2249.2000.01183.x

Musch, E., Lutfi, T., von Stein, P., Zargari, A., Admyre, C., Malek, M., et al. (2013). Topical treatment with the Toll like receptor agonist DIMS0150 has potential for lasting relief of symptoms in patients with chronic active ulcerative colitis by restoring glucocorticoid sensitivity. Inflamm. Bowel Dis. 19, 283-292. doi: 10.1002/ibd.23019

Nalleweg, N., Chiriac, M. T., Podstawa, E., Lehmann, C., Rau, T. T., Atreya, R., et al. (2015). IL-9 and its receptor are predominantly involved in the pathogenesis of UC. Gut 64, 743-755. doi: 10.1136/gutjnl-2013-305947

Neurath, M. F. (2014). Cytokines in inflammatory bowel disease. Nat. Rev. Immunol. 14, 329-342. doi: 10.1038/nri3661

Neurath, M. F., Pettersson, S., Meyer zum Buschenfelde, K. H., and Strober, W. (1996). Local administration of antisense phosphorothioate oligonucleotides to the p65 subunit of NF-kappa B abrogates established experimental colitis in mice. Nat. Med. 2, 998-1004. doi: 10.1038/nm0996-998

Ng, S. C., Shi, H. Y., Hamidi, N., Underwood, F. E., Tang, W., Benchimol, E. I., et al. (2018). Worldwide incidence and prevalence of inflammatory bowel disease in the 21 st century: a systematic review of population-based studies. Lancet 390, 2769-2778. doi: 10.1016/S0140-6736(17)32448-0

Ohtani, K., Ohtsuka, Y., Ikuse, T., Baba, Y., Yamakawa, Y., Aoyagi, Y., et al. (2010). Increased mucosal expression of GATA-3 and STAT-4 in pediatric ulcerative colitis. Pediatr. Int. 52, 584-589. doi: 10.1111/j.1442-200X.2009.03019.x

Popp, V., Gerlach, K., Mott, S., Turowska, A., Garn, H., Atreya, R., et al. (2016). Rectal delivery of a DNAzyme that specifically blocks the transcription factor GATA3 reduces colitis in mice. Gastroenterology 152, 176-192.e5. doi: 10.1053/j.gastro.2016.09.005

Powrie, F., Carlino, J., Leach, M. W., Mauze, S., and Coffman, R. L. (1996). A critical role for transforming growth factor-beta but not interleukin 4 in the suppression of T helper type 1-mediated colitis by CD45RB(low) CD4 T cells. J. Exp. Med. 183, 2669-2674. doi: 10.1084/jem.183.6.2669

Rachmilewitz, D., Karmeli, F., Takabayashi, K., Hayashi, T., Leider-Trejo, L., Lee, J., et al. (2002). Immunostimulatory DNA ameliorates experimental and spontaneous murine colitis. Gastroenterology 122, 1428-1441. doi: 10.1053/gast.2002.32994

Reinisch, W., Hung, K., Hassan-Zahraee, M., and Cataldi, F. (2018). Targeting endothelial ligands: (ICAM-1/Alicaforsen, MAdCAM-1). J. Crohn Colitis 12, S669-S677. doi: 10.1093/ecco-jcc/jjy059

Rieder, F., Zimmermann, E. M., Remzi, F. H., and Sandborn, W. J. (2013). Crohn's disease complicated by strictures: a systematic review. Gut 62, 1072-1084. doi: 10.1136/gutjnl-2012-304353

Rivera-Nieves, J., Gorfu, G., and Ley, K. (2008). Leukocyte adhesion molecules in animal models of inflammatory bowel disease. Inflamm. Bowel Dis. 14, 1715-1735. doi: 10.1002/ibd.20501

Roda, G., Jharap, B., Neeraj, N., and Colombel, J. F. (2016). Loss of response to antiTNFs: definition, epidemiology and management. Clin. Translat. Gastroenterol. 7:e135. doi: 10.1038/ctg.2015.63

Sands, B. E. (2017). Leukocyte anti-trafficking strategies: current status and future directions. Dig. Dis. 35, 13-20. doi: 10.1159/000449077

Schreiber, S., Nikolaus, S., Malchow, H., Kruis, W., Lochs, H., Raedler, A., et al. (2001). Absence of efficacy of subcutaneous antisense ICAM-1 treatment of chronic active Crohn's disease. Gastroenterology 120, 1339-1346. doi: 10.1053/gast.2001.24015

Stein, C. A., and Castanotto, D. (2017). FDA-approved oligonucleotide therapies in 2017. Mol. Ther. 25, 1069-1075. doi: 10.1016/j.ymthe.2017.03.023

Strober, W., Fuss, I., and Mannon, P. (2007). The fundamental basis of inflammatory bowel disease. J. Clin. Invest. 117, 514-521. doi: 10.1172/JCI30587

Suzuki, K., Arumugam, S., Yokoyama, J., Kawauchi, Y., Honda, Y., Sato, H., et al. (2016). Pivotal role of carbohydrate sulfotransferase 15 in fibrosis and mucosal healing in mouse colitis. PLOS ONE 11:e0158967. doi: 10.1371/journal.pone.0158967

Suzuki, K., Yokoyama, J., Kawauchi, Y., Honda, Y., Sato, H., Aoyagi, Y., et al. (2017). Phase 1 clinical study of siRNA targeting carbohydrate sulphotransferase 15 in Crohn's disease patients with active mucosal lesions. J Crohn Colitis 11, 221-228. doi: 10.1093/ecco-jcc/jjw143

Suzuki, K., Yokoyama, J., Kawauchi, Y., Honda, Y., Sato, H., Aoyagi, Y., et al. (2017). Phase 1 clinical study of siRNA targeting carbohydrate sulphotransferase 15 in Crohn's disease patients with active mucosal lesions. J. Crohns Colitis. 11, 221-228. doi: 10.1093/ecco-jcc/jjw143

Suzuki, K., and Yoneyama, H. (2017). New endoscopic approach of antifibrotic therapy for inflammatory bowel disease. Ann. Transl. Med. 5:191. doi: $10.21037 /$ atm.2017.03.65

Tiainen, J., and Matikainen, M. (1999). Health-related quality of life after ileal J-pouch-anal anastomosis for ulcerative colitis: long-term results. Scand. J. Gastroenterol. 34, 601-605. doi: 10.1080/003655299750026065

Vainer, B., and Nielsen, O. H. (2000). Changed colonic profile of Pselectin, platelet-endothelial cell adhesion molecule-1 (PECAM-1), intercellular adhesion molecule-1 (ICAM-1), ICAM-2, and ICAM3 in inflammatory bowel disease. Clin. Exp. Immunol. 121, 242-247. doi: 10.1046/j.1365-2249.2000.01296.x

van Deventer, S. J., Tami, J. A., and Wedel, M. K. (2004). A randomised, controlled, double blind, escalating dose study of alicaforsen enema in active ulcerative colitis. Gut 53, 1646-1651. doi: 10.1136/gut.2003.036160

van Deventer, S. J., Wedel, M. K., Baker, B. F., Xia, S., Chuang, E., Miner, P. B., et al. (2006). A phase II dose ranging, double-blind, placebo-controlled study of alicaforsen enema in subjects with acute exacerbation of mild to moderate left-sided ulcerative colitis. Aliment. Pharmacol. Ther. 23, 1415-1425. doi: 10.1111/j.1365-2036.2006.02910.x

Vegter, S., Tolley, K., Wilson Waterworth, T., Jones, H., Jones, S., and Jewell, D. (2013). Meta-analysis using individual patient data: efficacy and durability of topical alicaforsen for the treatment of active ulcerative colitis. Aliment. Pharmacol. Ther. 38, 284-293. doi: 10.1111/apt.12369 
Wan, Y. Y. (2014). GATA3: a master of many trades in immune regulation. Trends Immunol. 35, 233-242. doi: 10.1016/j.it.2014.04.002

Weigmann, B., and Neurath, M. F. (2017). Th9 cells in inflammatory bowel diseases. Semin. Immunopathol. 39, 89-95. doi: 10.1007/s00281-016-0603-Z

White, J. R., Phillips, F., Monaghan, T., Fateen, W., Samuel, S., Ghosh, S., et al. (2018). Review article: novel oral-targeted therapies in inflammatory bowel disease. Aliment. Pharmacol. Ther. 19:14669. doi: 10.1111/apt.14669

Yacyshyn, B., Chey, W. Y., Wedel, M. K., Yu, R. Z., Paul, D., and Chuang, E. (2007). A randomized, double-masked, placebo-controlled study of alicaforsen, an antisense inhibitor of intercellular adhesion molecule 1 , for the treatment of subjects with active Crohn's disease. Clin. Gastroenterol. Hepatol. 5, 215-220. doi: 10.1016/j.cgh.2006.11.001

Yacyshyn, B. R., Barish, C., Goff, J., Dalke, D., Gaspari, M., Yu, R., et al. (2002a). Dose ranging pharmacokinetic trial of high-dose alicaforsen (intercellular adhesion molecule-1 antisense oligodeoxynucleotide) (ISIS 2302) in active Crohn's disease. Aliment. Pharmacol. Ther. 16, 1761-1770. doi: 10.1046/j.1365-2036.2002.01341.x

Yacyshyn, B. R., Bowen-Yacyshyn, M. B., Jewell, L., Tami, J. A., Bennett, C. F., and Kisner, D. L. (1998). A placebo-controlled trial of ICAM-1 antisense oligonucleotide in the treatment of Crohn's disease. Gastroenterology 114, 1133-1142. doi: 10.1016/S0016-5085(98)70418-4

Yacyshyn, B. R., Chey, W. Y., Goff, J., Salzberg, B., Baerg, R., Buchman, A. L., et al. (2002b). Double blind, placebo controlled trial of the remission inducing and steroid sparing properties of an ICAM-1 antisense oligodeoxynucleotide, alicaforsen (ISIS 2302), in active steroid dependent Crohn's disease. Gut 51, 30-36. doi: 10.1136/gut.51.1.30

Zhang, Q., Lenardo, M. J., and Baltimore, D. (2017). 30 years of NF$\kappa \mathrm{B}$ : a blossoming of relevance to human pathobiology. Cell 12, 37-57. doi: 10.1016/j.cell.2016.12.012

Zorzi, F., Calabrese, E., Monteleone, I., Fantini, M., Onali, S., Biancone, L., et al. (2012). A phase 1 open-label trial shows that Smad7 antisense oligonucleotide
(GED0301) does not increase the risk of small bowel strictures in Crohn's disease. Aliment. Pharmacol. Ther. 36, 850-857. doi: 10.1111/apt.12051

Zundler, S., and Neurath, M. F. (2017). Novel insights into the mechanisms of gut homing and antiadhesion therapies in inflammatory bowel diseases. Inflamm. Bowel Dis. 23, 617-627. doi: 10.1097/MIB.00000000 00001067

Conflict of Interest Statement: RA reports grants or personal fees from AbbVie, Biogen, Boehringer Ingelheim GmbH \& Co. KG, Cellgene, DrFalk Pharma GmbH, Ferring GmbH, GlaxoSmithKline plc, InDex Pharmaceuticals AG, Janssen-Cilag GmbH, MSD Sharp \& Dome GmbH, Philogen, Pfizer Inc., Roche Pharma, Samsung Bioepsis, Stelic Institute, Sterna Biologicals, Takeda Pharma GmbH \& Co. KG, and Tillotts Pharma AG outside the submitted work. MN reports personal fees from MSD Sharp \& Dohme GmbH, PPM Services S.A., Index Pharmaceuticals $\mathrm{AB}$, Shire $\mathrm{GmbH}$, Boehringer Ingelheim $\mathrm{GmbH} \& \mathrm{Co}$. KG, Janssen Cilag GmbH, Pentax Europe GmbH, Tillotts Pharma AG, e.Bavarian Health GmbH, Takeda Pharma GmbH \& Co. KG, and grants from German Research Council, German Cancer Aid, outside the submitted work. GM has served as an advisory board member for ABBVIE.

The remaining authors declare that the research was conducted in the absence of any commercial or financial relationships that could be construed as a potential conflict of interest.

Copyright (c) 2019 Scarozza, Schmitt, Monteleone, Neurath and Atreya. This is an open-access article distributed under the terms of the Creative Commons Attribution License (CC BY). The use, distribution or reproduction in other forums is permitted, provided the original author(s) and the copyright owner(s) are credited and that the original publication in this journal is cited, in accordance with accepted academic practice. No use, distribution or reproduction is permitted which does not comply with these terms. 